\title{
A Dynamic Kinetic C-P Cross-Coupling for the Asymmetric Synthesis of Axially Chiral P,N Ligands
}

\author{
Pedro Ramírez-López, ${ }^{\S}$ Abel Ros, ${ }^{*}{ }^{\S}$ Beatriz Estepa, ${ }^{\jmath}$ Rosario Fernández, ${ }^{*,}$ Béla Fiser, Enrique Gómez- \\ Bengoa, ${ }^{*, \neq}$ José M. Lassaletta ${ }^{* \S}$ \\ ${ }^{\S}$ Instituto Investigaciones Químicas (CSIC-US), C/ Américo Vespucio, 49, 41092 Sevilla, Spain.

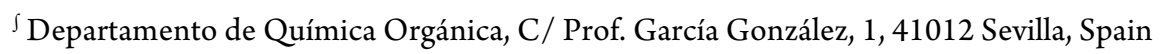 \\ ‡ Departamento de Química Orgánica I, Universidad del País Vasco, UPV/EHU, Apdo. 1072, 20080 San Sebastián, Spain
}

\begin{abstract}
The Pd-catalyzed enantioselective C-P cross-coupling between racemic, configurationally stable heterobiaryl triflates and trialkylsilyldiaryl(dialkyl)phosphines has been used for the synthesis of several families of enantiomerically enriched heterobiaryl phosphines including QUINAP, PINAP, and QUINAZOLINAP analogues, which can be performed with good yields and enantioselectivities using JOSIPHOS-type bidentate phosphines. The strategy relies on two key assumptions: (I) the $\mathrm{N}$-atom of the heterocycle is a better ligand than triflate and, upon oxidative addition, it incorporates into the coordination sphere of the $\mathrm{Pd}^{\mathrm{II}}$ center to form cationic cyclic intermediates, and (II) the geometry of the palladacycle results in a widening of the angles involved in the stabilization of the stereogenic axis, facilitating a fast interconversion of diastereomeric structures and, hence, a dynamic kinetic C-P cross-coupling reaction. These starting hypotheses are supported by experimental and computational studies.
\end{abstract}

KEYWORDS: P,N-ligands, QUINAP, DYKAT, Asymmetric Catalysis, C-P coupling, Silylphosphines, Heterobiaryls

\section{INTRODUCTION}

Axially chiral P,N-ligands have found important applications in the field of asymmetric catalysis. Since the pioneering developments by Brown and co-workers on $\mathrm{Rh}^{\mathrm{I}}$-catalyzed asymmetric hydroboration/oxidation of styrenes, ${ }^{1}$ the original ligand QUINAP I and related axially chiral P,N-ligands have found many other applications in asymmetric catalysis, including $\mathrm{Rh}^{\mathrm{I}}$-catalyzed hydroboration/amination, ${ }^{2} \mathrm{Rh}^{\mathrm{I}}$-catalyzed diboration of alkenes, ${ }^{3}$ $\mathrm{Cu}^{\mathrm{I}}$-catalyzed conjugate boration, ${ }^{4} \mathrm{Ag}^{\mathrm{I}}$-catalyzed 1,3-dipolar cycloadditions, ${ }^{5} \quad \mathrm{Ni}^{0}$-catalyzed cycloaddition of 1,2,3,4benzothiatriazine-1,1 $(2 \mathrm{H})$-dioxides with allenes, ${ }^{6} \mathrm{Cu}^{1}-$ catalyzed 1,2 -addition of alkynes to enamines ${ }^{7}$ or iminium ions, ${ }^{8}$ or $\mathrm{Cu}^{1}-$ catalyzed conjugate addition to alkylidene Meldrum's acids ${ }^{9}$ (Scheme 1).

In spite of the excellent ligand properties exhibited by QUINAP, its resolution via stoichiometric $\mathrm{Pd}^{\mathrm{II}}$ complexes ${ }^{10}$ has been a serious drawback that has humpered its application by the chemical industry. Even being commercially available, its high price has probably excluded its structure from being a common candidate in many exploratory screenings at average research laboratories. A second aspect that has retarded the development of applications for axially chiral P,N-ligands has been the lack of structural variability, as for years QUINAP itself and a few analogues differing in the diarylphosphino group ${ }^{9 b}$ have been the only available option. These problems have motivated the development of alternative axially chiral P,N ligands, on one side, and studies directed to improve the efficiency and economy of the synthetic methods, on the other. Thus, the groups of Guiry, Carreira, Apponik, Chan and others

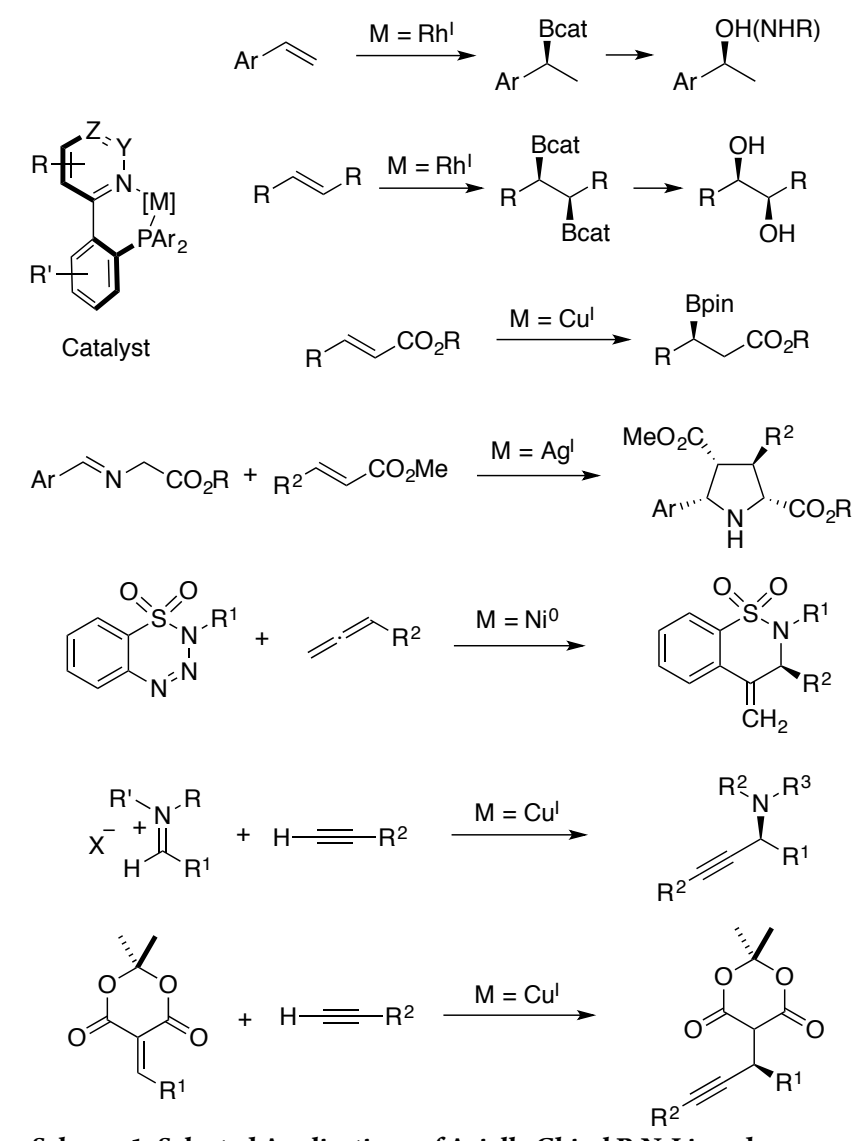

Scheme 1. Selected Applications of Axially Chiral P,N-Ligands 


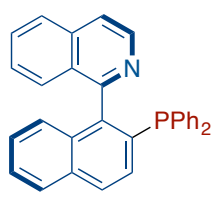

I: QUINAP Brown

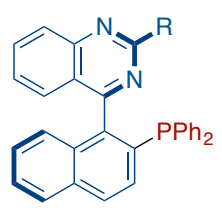

II: QUINAZOLINAP Guiry

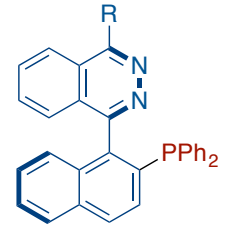

III: PINAP Carreira<smiles>Cc1cccnc1-c1c(P)cc(Br)cc1C(C)(C)C</smiles>

IV: PyPHOS Chan

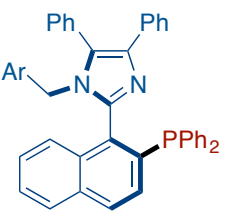

V: StackPHOS Aponick

\section{Figure 1. Families of Axillay Chiral P,N-Ligands}

have approached the problem by introducing alternative ligands such as QUINAZOLINAP II, ${ }^{11}$ PINAP III, ${ }^{12}$ PyPHOS IV, ${ }^{13}$ and StackPHOS $\mathbf{V}^{14}$ (Figure 1). These ligands have also been succesfully applied in asymmetric catalysis, matching or improving in some cases the results collected with QUINAP in previously developed or new catalytic reactions. However, the methods required for their synthesis are still far from practical: in the best cases the synthesis requires resolution of diastereomers by chromatography or crystallization (PINAP), ${ }^{12}$ while most of them (QUINAZOLINAP, ${ }^{10}$ PyPHOS, ${ }^{12}$ and StackPHOS ${ }^{13}$ ) have to be prepared by crystallization of stoichiometric amounts of $\mathrm{Pd}$ (II) complexes.

Alternative approaches to the synthesis of QUINAP have also been reported. The first practical synthesis avoiding the use of halfequivalents of Pd salts was reported in 2007 by Knochel and coworkers, who exploited the easy chromatographic separation of diastereomeric sulfoxide intermediates, and their easy transformation into enantiopure QUINAP after sulfoxide-lithium exchange, quenching with $\mathrm{Ph}_{2} \mathrm{PCl}$ and sulfur, and reduction with Raney-Ni. ${ }^{15}$ Two years later, Clayden and co-workers ${ }^{16}$ went a step further and, taking advantage of the stereochemical control by the sulfinyl group in heterobiaryl sulfoxides, succeeded in the development of a 'dynamic thermodynamic resolution' leading to QUINAP after the functional group transformations mentioned above. This constitutes the first asymmetric synthesis of QUINAP, but still requires the introduction of an enantiopure sulfinyl group as a sacrificial auxiliary.

Therefore, there is still demand of a general methodology for the synthesis of axially chiral heterobiaryls, ideally based on a catalytic asymmetric procedure enabling the introduction of structural variability at both the heterocycle and the diaryl(dialkyl)phosphino group. The direct construction of the stereogenic axis by a crosscoupling reaction might appear as the most straightforward approach to these systems. However, in spite of the great progress achieved during the last years in asymmetric Suzuki-Miyaura crosscouplings, ${ }^{17}$ the reaction using heterocyclic substrates remains as an unsolved synthetic challenge, presumably due to the interferences caused by the coordination of the heteroatoms located on the substrate, the limitations associated with the availability and poor stability of heteroaromatic organometallics, and the lower configurational stability of the products compared to standard biaryls. ${ }^{18}$ In the frame of our research program in asymmetric cross-coupling reactions, we recently developed an alternative methodology for the asymmetric synthesis of axially chiral heterobiaryls consisting of a dynamic asymmetric Suzuki-Miyaura coupling (DYKAT) between racemic, configurationally stable heterobiaryl triflates and arylboroxines (Scheme 2, eq. 1). ${ }^{19}$ In a parallel work, we started investigations to apply this strategy for $\mathrm{C}-\mathrm{P}$ bond forming reactions ${ }^{20}$ while, simultaneously, Virgil, Stoltz, et al. also reported the enantioselective synthesis of QUINAP according to a similar procedure $^{21}$ (eq. 2) In both cases, a single example (QUINAP itself) was reported, and different mechanisms involved in the dynamic kinetic cross-coupling were invoked. In this paper, an expanded, general procedure for the synthesis of enantiomerically enriched isoquinoline, 3-methylpyridine, quinazoline and phtalazine derivatives is reported (eq. 3), along with experimental and computational support for a mechanism based on the labilization of cyclic, cationic oxidative addition intermediates.

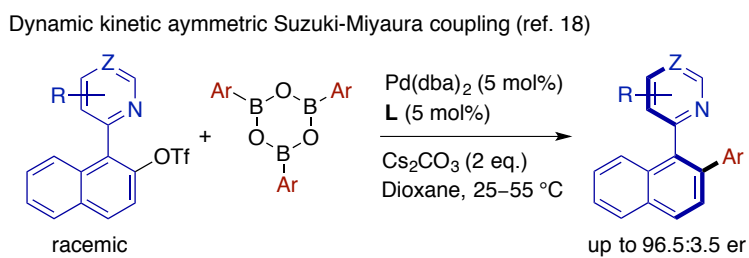

Preliminary results on dynamic kinetic asymmetric C-P bond formation (refs. 19 \& 20)

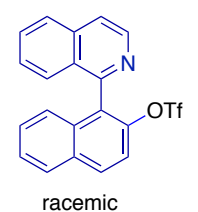

racemic

This work

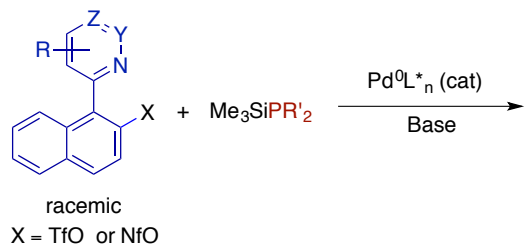

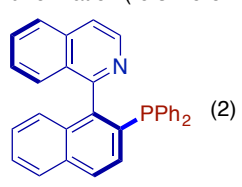

I: up to $95: 5$ er (2)

Scheme 2. DYKAT Techniques for the Asymmetric Synthesis of Heterobiaryls

\section{RESULTS AND DISCUSSION}

Starting Hypothesis and Method Development. Basically, our strategy is based in two key assumptions: 1) thanks to the poor coordinating ability of the triflate anion, the oxidative addition of $\mathrm{Pd}^{0} \mathrm{LL}$ catalysts $\left[\mathrm{LL} \mathrm{L}^{\prime}=\right.$ chiral ligand $\left.(\mathrm{s})\right]$ should generate cyclic cationic intermediates $\mathbf{O A I}$ and $\mathbf{O A I}$ ' incorporating the isoquinoline/pyridine $\mathrm{N}$ atom as a ligand (Scheme 3 ) and 2) a widening of the angles $\varphi_{1}$ and $\varphi_{2}$ would compromise the configurational stability of the stereogenic axis, facilitating an easy equilibration of atropoisomeric intermediates $\mathbf{O A I}$ and $\mathbf{O A I}$ '. In this scenario, two additional conditions are required to achieve a highly enantioselective dynamic kinetic C-P coupling to products $\mathbf{P}$ or $\mathbf{P}$ ': 3 ) the transmetalation step from both $\mathbf{O A I}$ and $\mathbf{O A I}$ into intermediates TI and TI' should be relatively slow with respect to the interconversion between OAI and OAI' and 4) the chiral ligand(s) LL' should provide a substantial energy gap between the diastereomeric transmetallation transition states.

Our initial ligand screening was performed using the coupling of triflate $\mathbf{1 A}$ and $t \mathrm{BuMe}_{2} \mathrm{SiPPh}_{2} \mathbf{2}^{22}$ as a model reaction, with $\mathrm{CsF}$ as the base, ${ }^{23}$ dry THF at $55^{\circ} \mathrm{C}$ as the solvent and 5 mol\% 

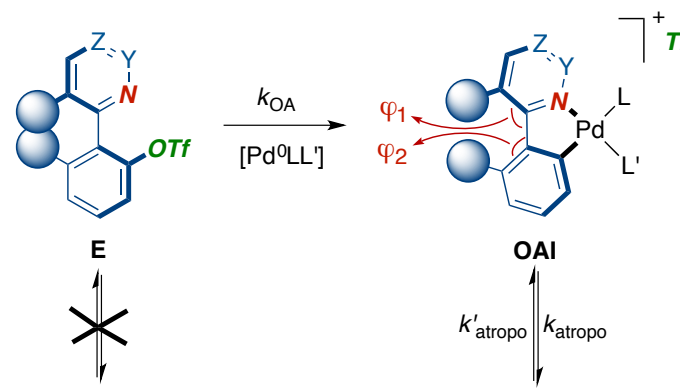

$k_{\text {atropo }}^{\prime} k_{\text {atropo }}$

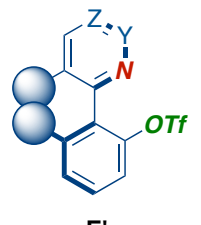

$E^{\prime}$

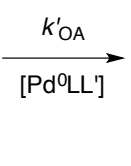

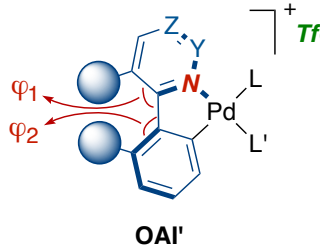

OAI'
$\underset{\mathrm{MPR}_{2}}{k_{\mathrm{T}}}$

TI

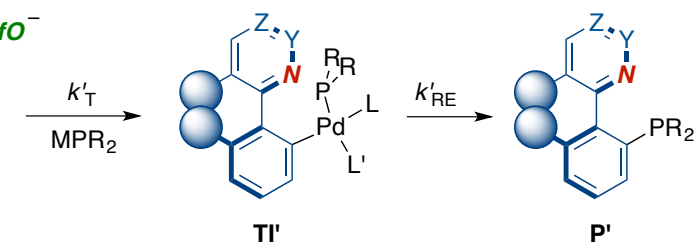

Scheme 3. Starting Mechanistic Hypothesis

$\mathrm{Pd}_{2}(\mathrm{dba})_{3} / 10 \mathrm{~mol} \%$ ligand as the catalyst system (Scheme 4$)$. The use of silylphosphine reagents, ${ }^{24}$ whose reactivities can be tuned by adjusting the steric and/or electronic properties of the silyl group, was envisaged as a potentially useful method to modulate the rate of release of the phosphine fragment: according with our strategy, a relatively slow transmetallation step is necessary to facilitate the equilibration of the oxidative addition intermediates. Bishydrazone and phosphino-hydrazone ligands $\mathbf{L} 1$ and $\mathbf{L} 2$, which showed very good enantioselectivities and activities in asymmetric SuzukiMiyaura cross-couplings, ${ }^{25}$ and a privileged ligand such as the phosphino oxazoline L3, were chosen as candidates and tested in the model reaction. These ligands provided moderate to excellent conversions into the desired product $\mathbf{3 A a}$, although low enantioselectivities were observed. Motivated by the excellent performance of these type of ligands in dynamic asymmetric (DYKAT) SuzukiMiyaura couplings, ${ }^{19}$ we also examined TADDOL-derived phosphoramidite ligand L4 and related binaphthol-derivatives L5 and L6. L5-L6 afforded 5Aa in $>90 \%$ conversions but with low enantioselectivities. Axially chiral, commercially available ligands such as BINAP, MeO-MOP, and SEGPHOS L7-L9 also provided high catalytic activity but only in the last case a low yet significant 63:37 er was observed. Additionally, a kind of 'autocatalytic' reaction promoted by QUINAP 3Aa formed during the reaction was also considered. Using commercially available (S)-QUINAP as the ligand, a moderate $\sim 65 \%$ conversion was observed after 20 hours and the product 3Aa was obtained with $67: 33 \mathrm{er}$, thus demonstrating that QUINAP itself can be used for its own synthesis, although in an inefficient manner. P-stereogenic ligands L10-L11 and Josiphos-type ligands with planar chilarity L12-L18 were also tested in the model reaction, yielding the desired product $3 \mathrm{Aa}$ with moderate to excellent conversions. The reactions with ligands $\mathbf{L 1 2}$ and L16 proved to be the most selective (er 77:23 and 78.5:21.5, respectively). Due to the higher activity of $\mathbf{L 1 2}$ ( $\sim 58$ and 34\% conversions after $6 \mathrm{~h}$ for $\mathbf{L 1 2}$ and L16, respectively), it was selected for the following optimization studies, devoted to explore the effect of the phosphorous reagent and the Pd precatalyst. Silylphosphines with different steric and electronic properties of the silyl fragment, as well as other phosphine sources such as $\mathrm{HPPh}_{2} \mathbf{6}$ and $\mathrm{KPPh}_{2} 7$ were tested in the model reaction $(\mathbf{1 A} \longrightarrow \mathbf{3 A a})$, using 2 equiv of $\mathrm{CsF}$, dry THF as the solvent and $10 \mathrm{~mol} \% \mathbf{L 1 2} / 5 \mathrm{~mol}^{2} \mathrm{Pd}_{2}(\mathrm{dba})_{3}$ as the catalyst (Table 1, entries 1-7). The size of the trialkylsilyl

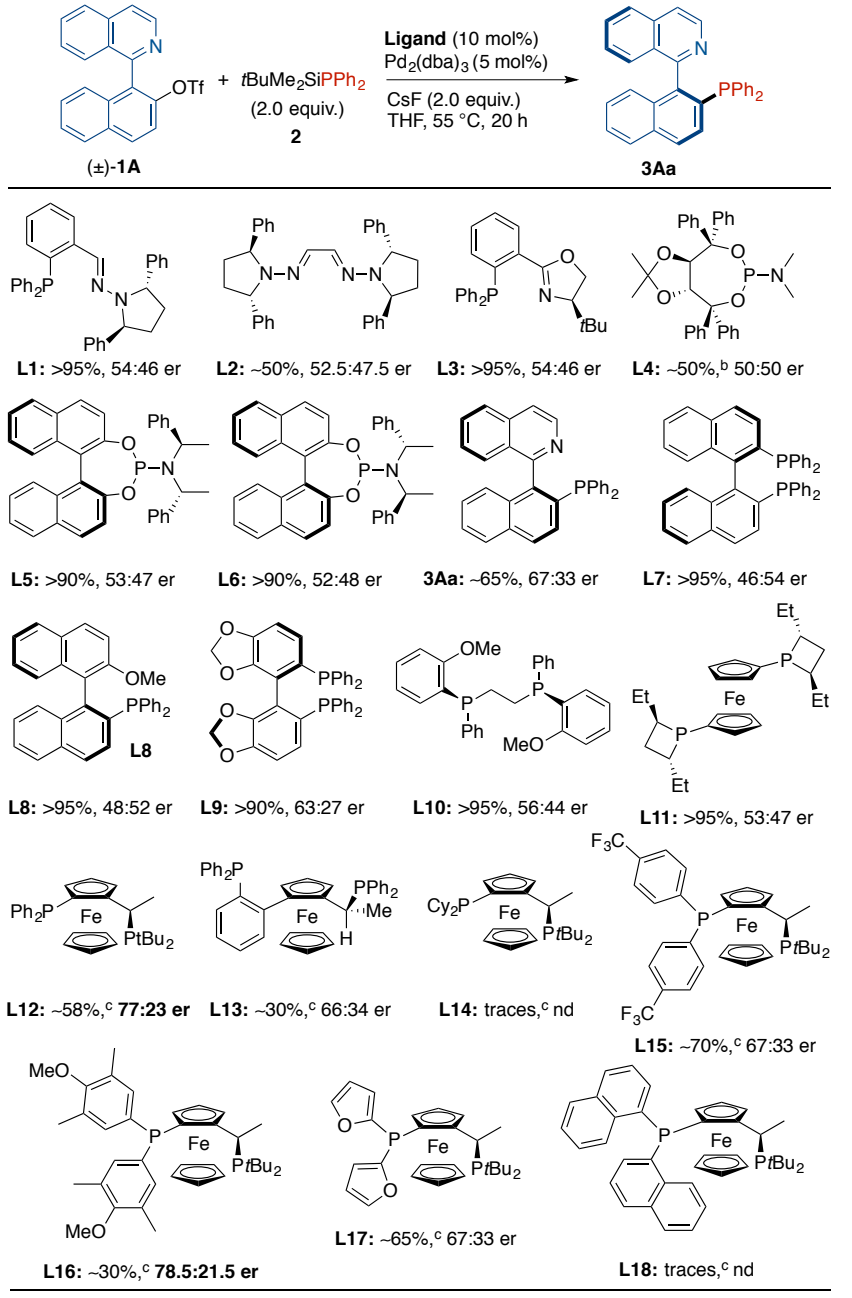

${ }^{a}$ Reactions performed at $0.1 \mathrm{mmol}$ scale in dry THF $(2 \mathrm{~mL})$. Conversions estimated by ${ }^{1} \mathrm{H}$ NMR. Enantiomeric ratios were determined by HPLC on chiral stationary phases after oxidation of 3Aa to the corresponding phosphine oxide. ${ }^{b}$ Reaction time was $38 \mathrm{~h} .{ }^{\mathrm{c}}$ Reaction time was $6 \mathrm{~h}$.

Scheme 4. Ligand Screening ${ }^{a}$ 
Table 1. Condition Optimization for the Synthesis of QUINAP

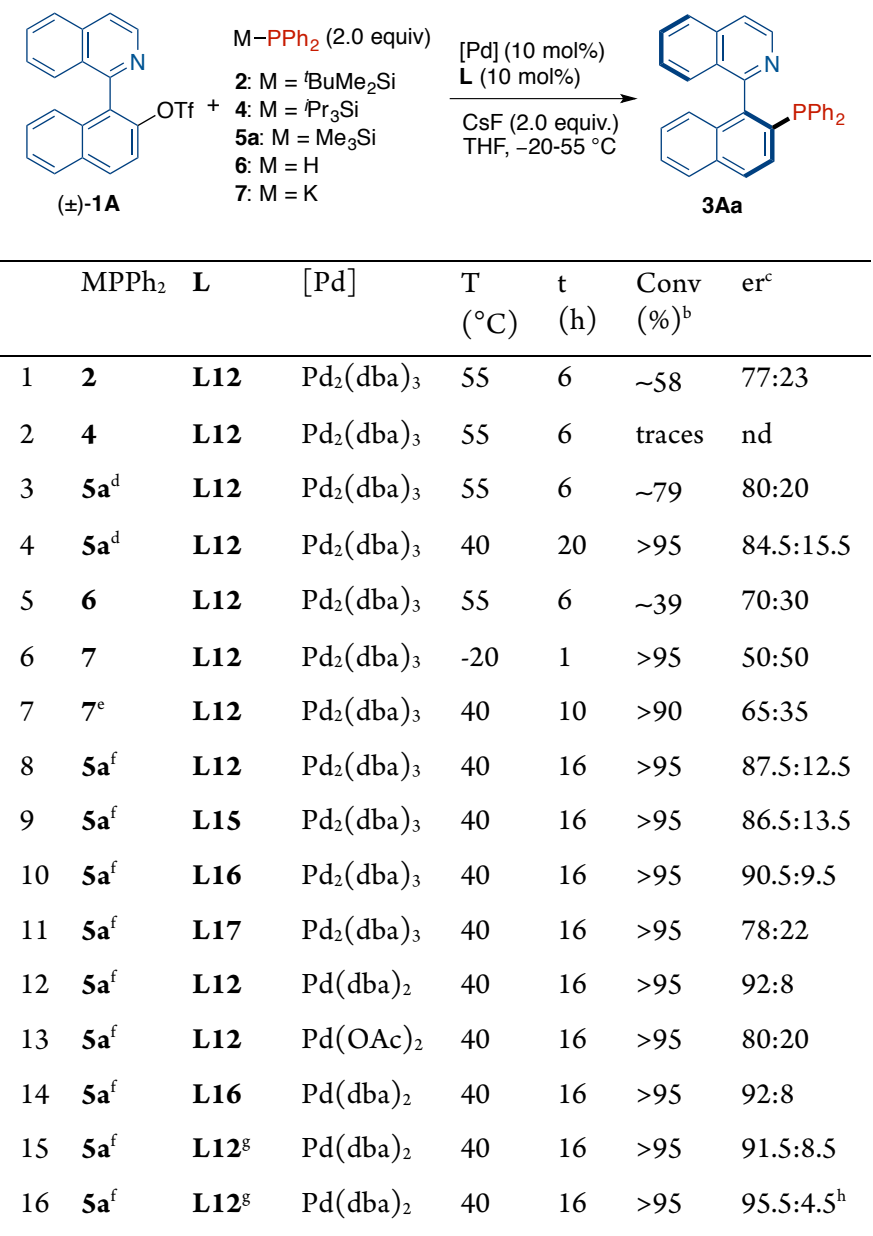

${ }^{a}$ Reactions performed on a $0.1 \mathrm{mmol}$ scale using anhydrous THF (2 $\mathrm{mL} / 0.1 \mathrm{mmol} \mathbf{1 A}), 2$ equiv phosphine source and 2 equiv of CsF. ${ }^{b}$ Conversions were estimated by $1 \mathrm{H}-\mathrm{NMR}$ and refer to the consumption of the starting triflate. ${ }^{c}$ Enantiomeric excesses were determined by HPLC on chiral stationary phases, after oxidation of 3Aa to the corresponding phosphine oxide. ${ }^{d}$ Commercially available $\mathrm{Me}_{3} \mathrm{SiPPh}_{2} \mathbf{5 a}$ from Aldrich containing $8 \%$ of $\mathrm{HPPh}_{2} 6$ was employed. e A $0.2 \mathrm{M}$ solution in THF of $\mathrm{KPPh}_{2} 7$ was slowly added $(0.1 \mathrm{~mL} / \mathrm{h})$ at $40{ }^{\circ} \mathrm{C}$ using a syringe pump, for a 10 hour-period. ${ }^{\mathrm{f}}$ Synthetic, $\mathrm{HPPh}_{2}$-free $\mathrm{Me}_{3} \mathrm{SiPPh}_{2}$ 5a was employed. ${ }^{\mathrm{g}} 20 \mathrm{~mol} \%$ of $\mathbf{L 1 2}$ was used. ${ }^{\mathrm{h}}$ Freshly prepared triflate $\mathbf{1 A}$ was used.

group proved to have a marked effect in the reactivity. Thus, strongly hindered $i \mathrm{Pr}_{3} \mathrm{SiPPh}_{2} 4^{22}$ afforded only traces of the desired product $3 \mathbf{A a}$ (entry 2). On the contrary, the smaller silyl group in $\mathrm{Me}_{3} \mathrm{SiPPh}_{2}$ 5a caused a remarkable increase of reactivity, while a moderate level of enantioselectivity was maintained (entry 3 ). In this case, the reaction temperature could be lowered to $40{ }^{\circ} \mathrm{C}$ to afford 3Aa with 84.5:15.5 er and quantitative conversion (entry 4). The use of alternative phosphine sources such as $\mathrm{HPPh}_{2} \mathbf{6}$ and $\mathrm{KPPh}_{2} 7$, commonly used in C-P coupling reactions, ${ }^{26}$ was also explored. In the first case, a low conversion $(-39 \%)$ and a moderate 70:30 er after 6 hours at $55^{\circ} \mathrm{C}$ were observed (entry 5). Due to the high basicity and nucleophilicity of $\mathrm{KPPh}_{2} 7$, we decided to carry out the reaction at low temperature to avoid secondary reactions. Surprisingly, 3Aa was formed in a quantitative manner after only 1 hour at $-20{ }^{\circ} \mathrm{C}$, although in racemic form (entry 6). This result was attributed to a relatively slow equilibration of OAI and OAI' inter- mediates at this temperature. Consequently, the reaction was performed at higher temperature $\left(40{ }^{\circ} \mathrm{C}\right)$, adding the reagent 7 over a 10 hour-period to achieve a high conversion into $\mathbf{3 A a}$ and with a moderate 65:35 er (entry 7). These experiments suggest that the activation of the $\mathrm{Si}-\mathrm{P}$ bond in the silylphosphines takes place after coordination of the silylphosphine to the palladium center, since a previous activation by the base $(\mathrm{CsF})$ would generate $\mathrm{Me}_{3} \mathrm{SiF}$ and $\mathrm{CsPPh}_{2}$, which should exhibit a similar reactivity to that of $\mathrm{KPPh}_{2}$. Accordingly, the reaction of $\mathbf{5 a}$ with $\mathrm{CsF}$ for $20 \mathrm{~h}$ at $40^{\circ} \mathrm{C}$ afforded a conversion of ca. $12 \%$ into $\mathrm{CsPPh}_{2}$ (estimated by ${ }^{31} \mathrm{P}-\mathrm{NMR}$ ), a much slower reaction than the C-P coupling. On the other hand, the addition of silylphosphine $\mathbf{5 a}$ to the reaction mixture results in an instantaneous color change from red to yellow, even at room temperature and/or in the absence of base, suggesting again a relatively fast coordination of the silylphosphine.

The analysis of different samples of commercially available $\mathrm{Me}_{3} \mathrm{SiPPh}_{2}$ 5a systematically showed contamination by variable amounts of $\mathrm{HPPh}_{2}$ 6, presumably causing a drop in the reactivity and enantioselectivity. Consequently, the use of synthetic $\mathrm{HPPh}_{2}$ free $\mathrm{Me}_{3} \mathrm{SiPPh}_{2}$ led to better reactivity and enantioselectivity (entry 8 ). The most selective Josiphos-type ligands from the original screening were then reexamined under the optimized conditions. Thus, ligands L15-L16 afforded similar results (er 86.5:13.5 and 90.5:9.5, respectively) as $\mathbf{L 1 2}$ (entries 9-10), but the selectivity dropped considerably with $\mathbf{L} 17$ (78:22 er, entry 11). The effect by the Pd precatalyst was also investigated. The selectivity dropped when $\mathrm{Pd}(\mathrm{OAc})_{2}$ was used but, interestingly, the use of mononuclear $\mathrm{Pd}(\mathrm{dba})_{2}$ provided slightly better enantioselectivities than the dinuclear $\mathrm{Pd}_{2}(\mathrm{dba})_{3}$ form for both $\mathbf{L 1 2}$ (entries 8 vs. 12) and $\mathbf{L 1 6}$ (entries 10 vs. 14). As commented before, the displacement of the chiral ligand used in the reaction by the QUINAP formed "in situ" was considered. An additional experiment using a 2:1 L12 $/ \mathrm{Pd}(\mathrm{dba})_{2}$ ratio had no significant effect on the enantioselectivity, suggesting that there is no transligation in the reaction medium (entry 15). It is important to highlight that the reaction is very sensitive to the quality of the THF. Freshly distilled and deoxygenated THF was needed to get high reproducible enantioselectivities (see Supp Inf for experimental details), whereas using THF dried over $\mathrm{Na}$ and stored for days in a Young's ampoule caused a significant drop in enantioselectivity (er from 92:8 to 72.5:27.5). Taking into account that the reproducibility of this DYKAT C-P crosscoupling protocol in terms of enantioselectivity depends on aspects such as purity of both THF and silyl reagents we also examined the influence of the starting triflate and, to our delight, we observed that $\left(S\right.$-QUINAP $3 \mathbf{A a}^{27}$ could be obtained with 95.5:4.5 er in excellent isolated yield when freshly prepared and purified isoquinoline-derived triflate $\mathbf{1 A}^{28}$ was employed (entry 16). Under these optimized conditions, the model reaction was analyzed at aprox. $50 \%$ conversion, leading to the product $\mathbf{3 A a}$ in $96: 4 \mathrm{er}$, while the unreacted material 1A had a 68:32 er. This result rules out a mechanism relying on a fast racemization of $\mathbf{1 A}$ (dynamic kinetic resolution).

Further efforts were directed to extend the scope of the methodology to related systems. To this aim, silylphosphines 5a-e were synthesized by a modified protocol of the described procedure ${ }^{29}$ and reacted with heterobiaryl triflates $1 \mathbf{A}-\mathbf{D}$ or nonaflates $\mathbf{8 C}-\mathbf{D}$ in the presence of $\mathrm{Pd}(\mathrm{dba})_{2} / \mathbf{L} \mathbf{1 2}$ as the catalytic system and $\mathrm{CsF}$ as the base. Heterobiaryl phosphines 3 were obtained in excellent yields and good enantiomeric excesses (Table 2). Silylphosphines

Table 2. Dynamic Kinetic Asymmetric C-P Couplings: Scope ${ }^{a}$ 


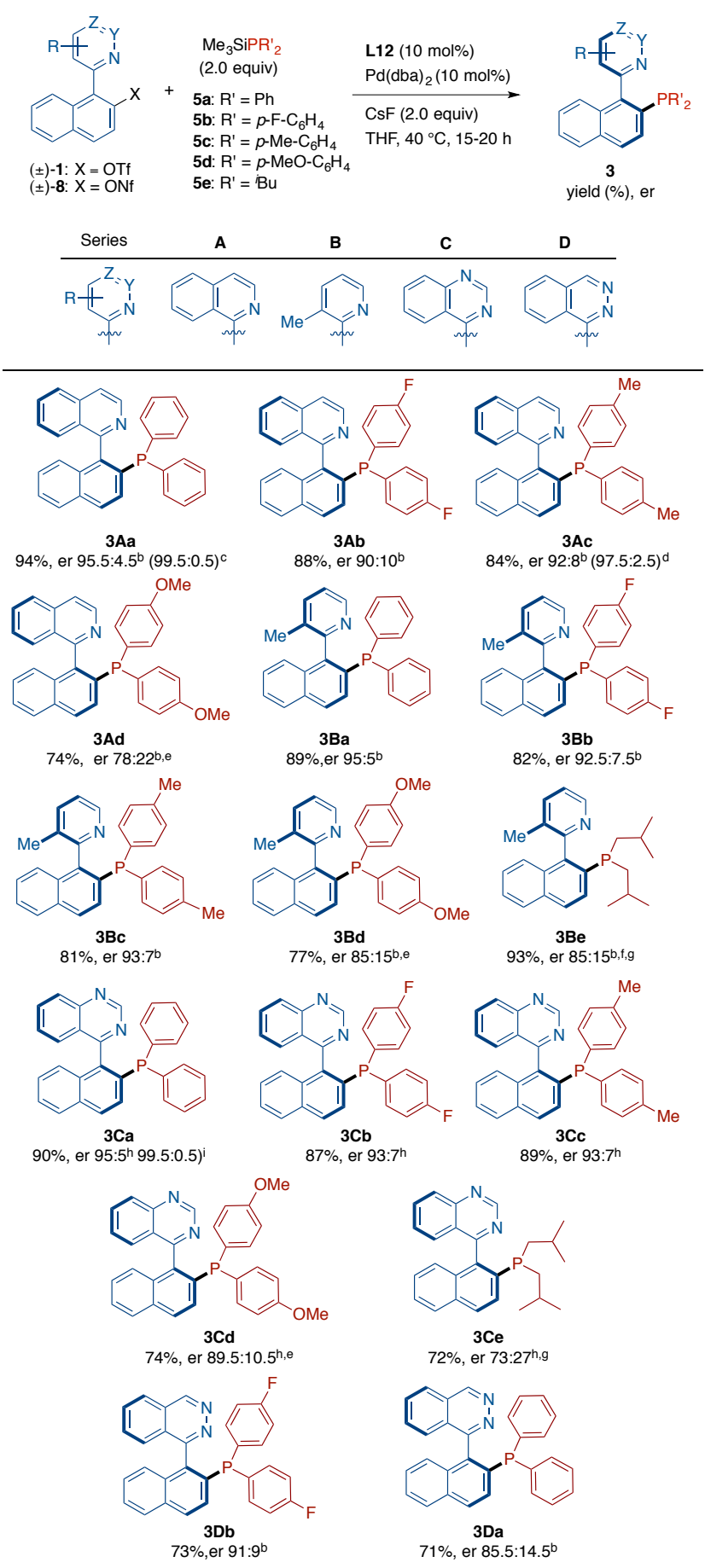

${ }^{a}$ Reactions performed on a $0.1 \mathrm{mmol}$ scale. Synthetic and phosphinefree silylphosphines 5a-e were used in all cases. Isolated yields and er's determined by HPLC on chiral stationary phases are shown. ${ }^{\mathrm{b}}$ Triflate 1 was used as starting material. ${ }^{\mathrm{C}} \mathrm{Er}$ after recrystalization (toluene $\left./ \mathrm{CH}_{2} \mathrm{Cl}_{2}\right)$. ${ }^{\mathrm{d}} \mathrm{Er}$ of mother liqour after crystalization of minor amounts of racemate ( $n$-hehane/AcOEt). ${ }^{\mathrm{e}}$ Air-sensitive compounds: fast flash chromatography under nitrogen was required for purification. ${ }^{\mathrm{f}} \mathbf{L} 16$ was used instead of L12. ${ }^{\mathrm{h}}$ Nonaflate 8 was used as starting material. ${ }^{\mathrm{g}}$ Reaction time 40 hours. ${ }^{\mathrm{i}}$ Er after washing with cold acetone.

5b-d, which bear electron withdrawing and electron-donating groups on the aryl fragment, afforded the corresponding chiral phosphines 3Ab-3Ad in 74-88\% isolated yields and er's from 78:22 to 92:8. Pyridine-derived phosphines $\mathbf{3 B a - B d}$ were also obtained in excellent yields and enantioselectivities (er 85.5:14.5-95:5). Additionally, the heterobiaryl dialkylphosphine 3Be could also be obtained in 93\% yield and a good 85:15 er when $\mathbf{L 1 6}$ was used as the ligand. Reproducibility problems were observed when triflate 1C was employed as the substrate, due presumably to some undetected impurity. In this case, we resorted to using nonaflate $\mathbf{8 C},{ }^{30}$ which allowed to obtain the desired products $\mathbf{3 C a}-\mathbf{3 C d}$ in excellent yields and enantioselectivities of 79-90\%. Dialkyl heterobiarylphosphine 3Ce was obtained in 72\% yield and a moderate 72.5:27.5 er. Phthalazine-derived triflate 1D was also tested in the C-P coupling reaction, giving the corresponding biaryl-phosphines 3Da-3Db in 71 and $73 \%$ yield, and 85.5:14.5 and 91:9 er, respectively. The enantiomeric purity of products 3 could be increased by crystallization in some cases. As representative examples, QUINAP itself (3Aa) and 3Ca were obtained in 99.5:0.5 er after a single recrystallization or washing with cold acetone, respectively. In the case of 3Ac, the crystallization of small amount of the racemate served to increase the optical purity of the remaining mother liquors (up to 97.5:2.5 er after a single crystallization).

Mechanism and Computational Studies. In the preliminary investigations mentioned above, two different mechanisms were postulated to explain the observed dynamic asymmetric crosscoupling. On one side, our group assumed that the nitrogen atom of the isoquinoline coordinates to the Pd center, leading to diastereomeric, cyclic OAI and OAI' intermediates, displacing the poorly coordinating triflate anion. The geometry of these OA intermediates suggests that the equilibration proceeds via a transi-

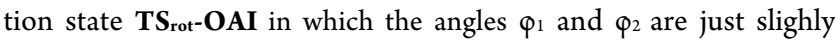
wider to allow hydrogen atoms $\mathrm{H}(8)$ and $\mathrm{H}\left(8^{\prime}\right)$ to reach coplanarity with the stereogenic axis (Scheme 5, path a). On the other hand, Virgil, Stoltz et al. ${ }^{21}$ suggested that unsaturated T-shaped $\mathbf{O A I}_{\mathbf{b}}$ and $\mathbf{O A I}_{\mathbf{b}}$ intermediates equilibrate via a square planar transition state TS rot-OAI $_{\mathbf{b}}$ stabilized by an agostic $\mathrm{Pd}-\mathrm{H}(8)$ interaction (path b).

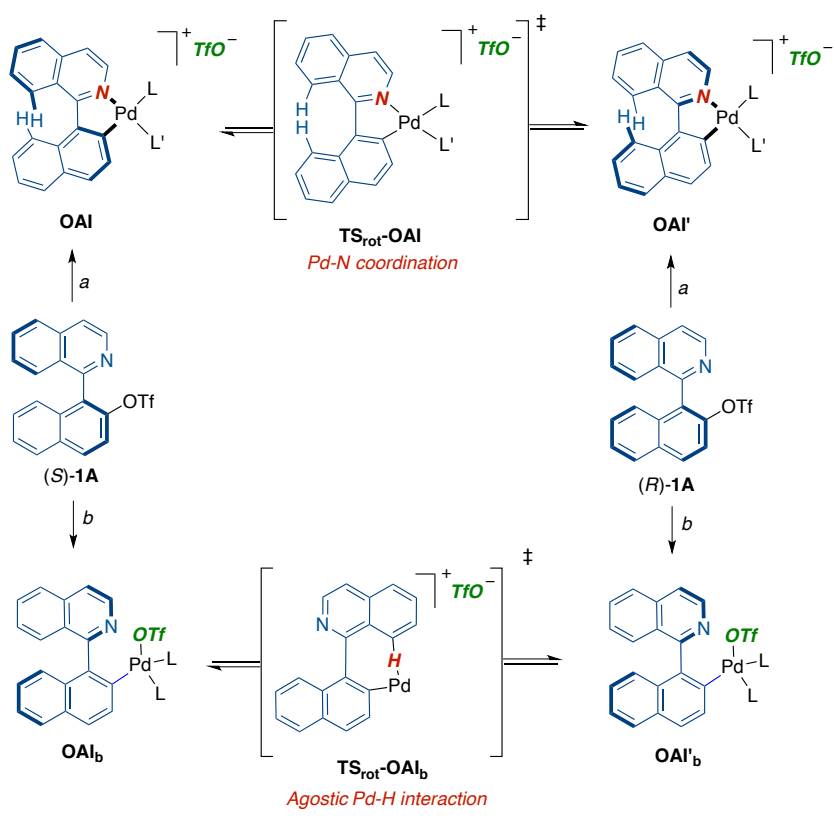

Scheme 5. Proposed Mechanisms for the Epimerization of Diastereomeric Oxidative Addition Intermediates.

In this last proposal, the presence of a coordinating nitrogen atom on the heteroaryl moiety does not play any role and the DYKAT process should work with triflate 9. However, no C-P 
coupling products was observed from the reaction of $\mathbf{9}$ with $\mathbf{5 a}$, which afforded an incomplete conversion into hydrolysis product 10 after overnight heating at $40^{\circ} \mathrm{C}$ (Scheme 6).

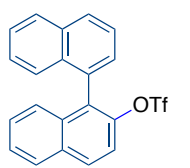

$( \pm)-9$

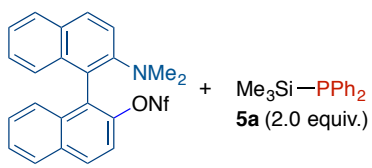

$( \pm)-11$

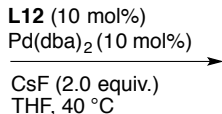

$\mathrm{THF}, 40^{\circ} \mathrm{C}$

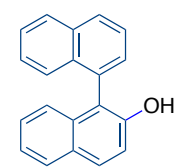

$( \pm)-10,70 \%$

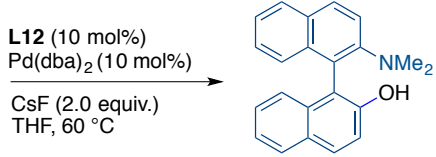

$( \pm)-12,10 \%$
Scheme 6. Experiments with Triflate 9 and Nonaflate 11.

This experiment reveals that the presence of a coordinating isoquinolyl/pyridyl nitrogen is not only necessary to favor the formation of the cationic and configurationally labile palladacycle, but also to facilitate the chelate-assisted oxidative addition of the racemic triflate/nonaflate to the $\mathrm{Pd}^{0}$ center. Similarly, the reaction of NOBIN-derived nonaflate $\mathbf{1 1}$ with $\mathbf{5 a}$ afforded a low conversion into hydrolysis product 12 , even at a higher temperature $\left(60^{\circ} \mathrm{C}\right)$, indicating that the formation of a five-membered cationic palladacycle is essential to reactivity.

In order to gain further insight into the mechanism of the reaction, we decided to set out an in depth DFT computational investigation of the process. According to the aforementioned data, the optimal experimental conditions involved the use of aromatic triflates or nonaflates as substrates, a Pd catalytic center bound to L12 or L16 as chiral ligands (both containing a second metal center, $\mathrm{Fe}$ ), and the combination of $\mathrm{Me}_{3} \mathrm{SiPPh}_{2}$ and $\mathrm{CsF}$ as phosphide transfer system. The sum of all these species would produce transition structures too large and complex to be computed by the current computational methods, if desirable accuracy has to be achieved. In order to maintain the system as close as possible to the experimental system, however, only a few simplifications were included in our study. We thus chose the model containing triflate $\mathbf{1 A}$ and $\mathrm{Pd}^{0}-\mathbf{L} 12$ chiral system, which has shown a good performance in the reaction (Tables 1-2), and the symmetrical triphenyl phosphine $\left(\mathrm{PPh}_{3}\right)$ as a model for the incoming nucleophilic phosphide during the transmetalation (vide infra). The calculations were performed at the B3LYP/6-31G** (LANL2DZ for Pd and Fe) level with the Gaussian 09 suite of programs. ${ }^{31,32}$ In this way, we were able to maintain the computational model as similar to the experimental one as possible, without compromising the accuracy of the method of choice.

We anticipated that the general mechanism to transform the initial racemic triflate $\mathbf{1 A}$ into the final enantioenriched QUINAP product would involve the three classical coupling steps, namely, oxidative addition, transmetalation and reductive elimination (Scheme 7). Our model is based on two central ideas; (i) the starting triflates $\boldsymbol{R}-\mathbf{1 A}$ and $\boldsymbol{S - 1 A}$ are configurationally stable, whereas the oxidative addition to $\operatorname{Pd}(0)$ leads to the formation of configurationally labile $\mathrm{Pd}(\mathrm{II})$ intermediates (int1), which are prone to epimerization, and (ii) the present DYKAT transformation is taking place under typical Curtin-Hammett conditions, meaning that the epimerization rate of the interconverting $\mathrm{Pd}(\mathrm{II})$ complexes (int 1, pro- $R$ and pro- $S$ ) is faster than their further evolution to int-
2 through transmetalation. Thus, the transmetalation step (TS2) is the stereodetermining one, and the two diastereomeric transmetalations must occur at sufficiently different rates as to induce enough selectivity in the formation of the final $R$ and $S$ products. Another important issue is that the reductive elimination process (TS3) must be fast again, making the transmetalation step irreversible.
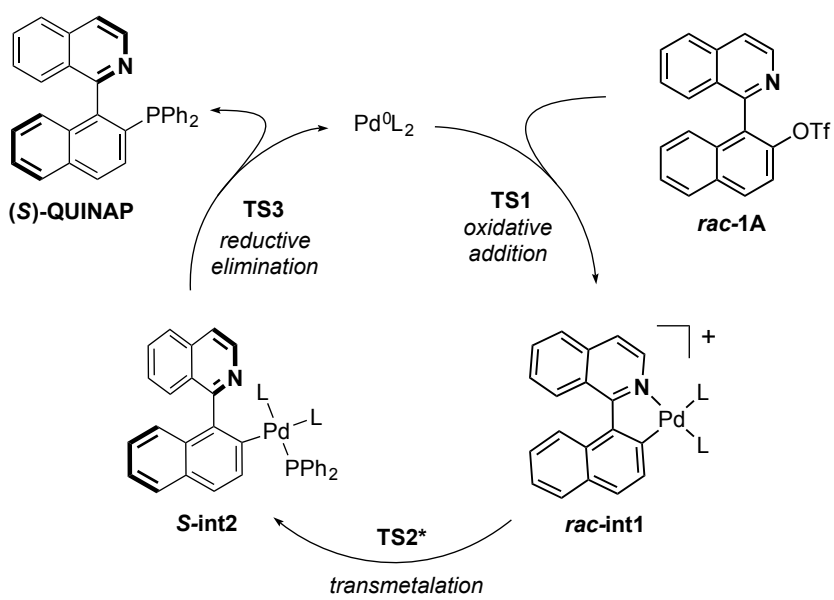

Scheme 7. General Mechanism for the Pd-Catalyzed QUINAP Formation

We found computational evidence supporting our working hypothesis based on the following results. The interconversion of the two enantiomeric triflates $\boldsymbol{R}-\mathbf{1 A}$ and $\boldsymbol{S}-\mathbf{1 A}$ is predicted to be an extremely slow process in the absence of palladium, since its activation energy is as high as $29.3 \mathrm{kcal} / \mathrm{mol}$ (TSrot-1A-anti, Scheme 8). There is a clear difficulty in the substrate to adopt the necessary conformation for the rotation. In the ground state, the angle formed by the planes of the two aromatic rings $\theta_{0}$ is ca. $90^{\circ}$, but it must approach to $0^{\circ}$ during the transition state $\mathbf{T S}_{\text {rot-1A }} \mathbf{A}$-syn (34.9 $\mathrm{kcal} / \mathrm{mol}$, Scheme 8), with the accompanying energetic cost. The rotation is easier through the anti approach, ${ }^{33}$ but still too high to be feasible at room temperature $(29.3 \mathrm{kcal} / \mathrm{mol}$, TS rot-1A-anti). Meanwhile, after the oxidative addition of $\operatorname{Pd}(0)$ to the C-OTf bond, the chelation complex $\boldsymbol{R}$-int 1- $\mathrm{PMe}_{3}$ presents drastic geometrical changes in the right direction to facilitate the rotation/epimerization process, like the reduction of the $\mathrm{q}_{1}$ angle to $45^{\circ}$ (Scheme 8). Furthermore, the N-Pd distance, which is a favorable, bonding interaction, is similar (ca. 2.1 $\AA$ ) in the ground states of $\boldsymbol{R}$ or $S$-int1- $\mathrm{PMe}_{3}$ and during the transition state for the rotation (TS rot-int1). Thus, the energy barrier is dramatically reduced to $18.7 \mathrm{kcal} / \mathrm{mol}$, explaining the fast interconversion of both enantiomeric complexes in the experimental conditions. These results are the confirmation that the palladacyclic intermediates can easily racemize whereas the initial triflates can not. 


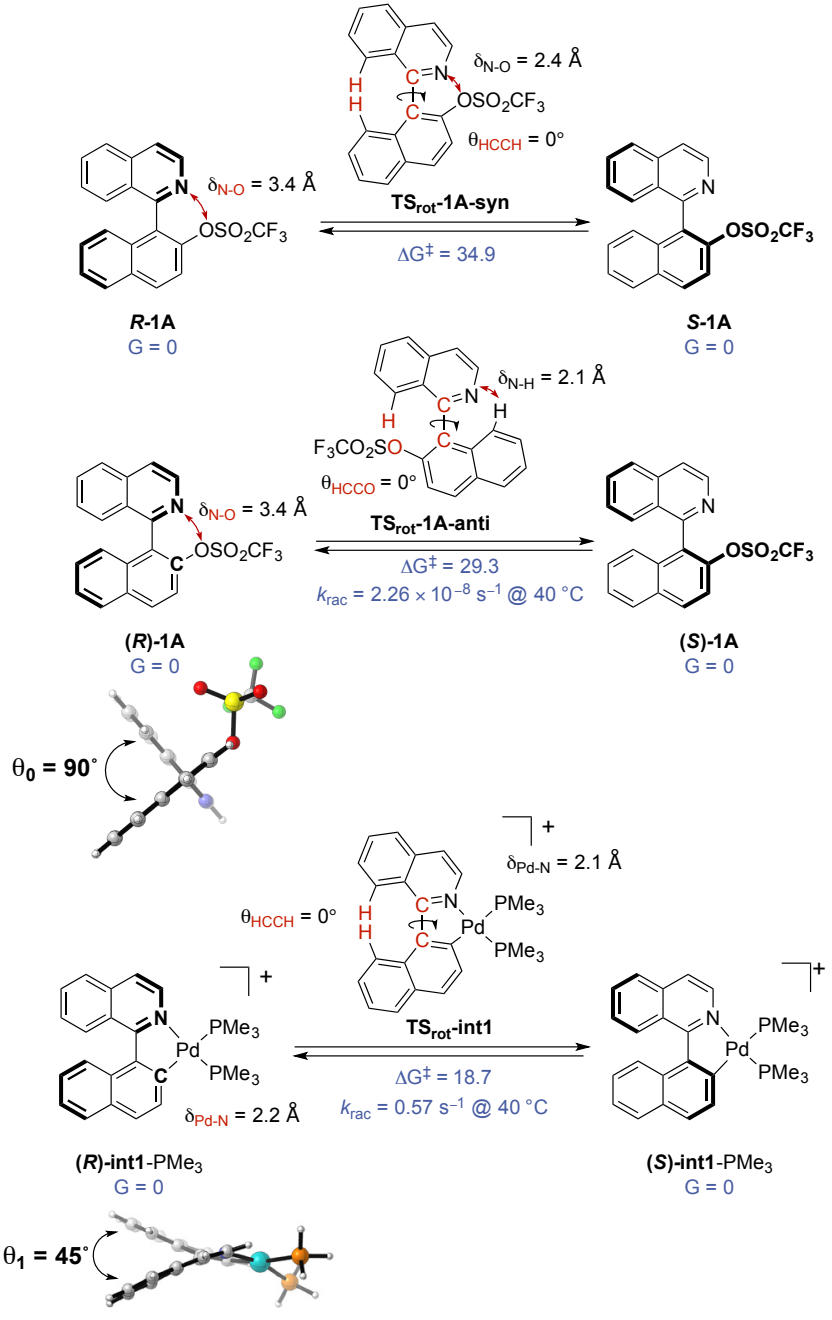

Scheme 8. Activation Energies for the Axial Rotation of Initial Triflates and Palladacyclic Intermediates.

The use of an achiral phosphine $\left(\mathrm{PMe}_{3}\right)$ as a first approximation implies that $\boldsymbol{R}$-int1- $\mathrm{PMe}_{3}$ and $\boldsymbol{S}$-int1- $\mathrm{PMe}_{3}$ are isoenergetic (Scheme 8), but the computation of the experimental chiral ligand $\mathbf{L 1 2}$ makes the corresponding complexes $R$-int1-L12 and S-int1L12 diastereomeric (Figure 2), differentiating their energies. Both complexes can still interconvert, and the equilibrium is clearly shifted towards the pro-R complex $R$-int1-L12, which is 4.3 $\mathrm{kcal} / \mathrm{mol}$ lower in energy than its pro-S counterpart. The two complexes in Figure 2 are actually the lowest in energy intermediates of a total of eight possible diastereomeric species, the rest of them being remarkably higher in energy (between 5.3 to $13.4 \mathrm{kcal} / \mathrm{mol}$ )

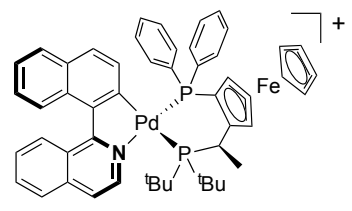

(S)-int1-L12 $\Delta \mathrm{G}=+4.3$

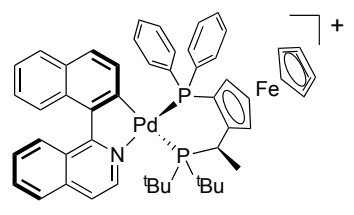

$(R)$-int1-L12
Figure 2. Structures of the Two Most Stable Palladacyclic Intermediates (int1) computed at M06/6$31+G(d, p)($ iefpcm,THF $) / /$ B3LYP/6-31G $(d, p)$ than $R$-int1-L12. Four of these species are the result of the fact that the palladium center is not forming a perfect square planar structure. The two cycles around the palladium atom are not coplanar, and form a pseudo-tetrahedral geometry with two different configurations. Also, the relative disposition of the two phosphorous atoms in the asymmetric di-phosphine (L12) with respect to the $C$ and $\mathrm{N}$ atoms of the aromatic rings leads to the formation of the other four diastereoisomers.

It is important to note that the overall lowest in energy intermediate ( $\boldsymbol{R}$-int1-L12) corresponds to the minor experimental enantiomer $R$. However, this fact is irrelevant in the present CurtinHammett conditions, since all possible isomers are involved in a fast equilibrium, and the final outcome of the reaction is determined by the relative activation energy of the different transmetalation transition states. At this point, attention must be drawn to the fact that the transmetalation step is not in fact a classical transmetalation, since it actually consists on a isoquinoline $/ \mathrm{Me}_{3} \mathrm{SiPPh}_{2}$ ligand exchange, with subsequent abstraction of the silyl moiety by the CsF salt (Scheme 9). This system is difficult to compute, but a slightly altered model was envisioned, consisting on the replacement of the actual $\mathrm{Me}_{3} \mathrm{SiPPh}_{2}$ ligand by $\mathrm{PPh}_{3}$ (int2-Si $v s$ int2- $\mathrm{Ph}$ ). This alternative has the great advantage that triphenylphosphine is conformationally much simpler than $\mathrm{Me}_{3} \mathrm{SiPPh}_{3}$, while maintaining a similar steric hindrance.

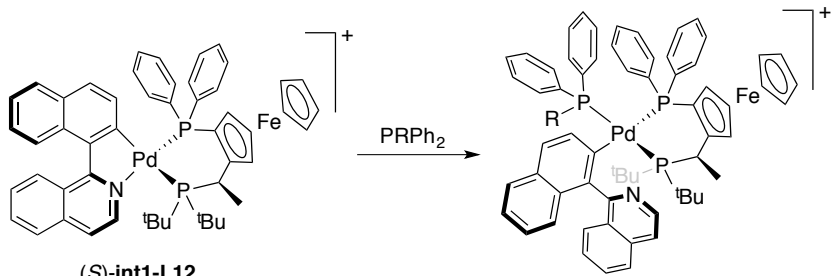

(S)-int1-L12
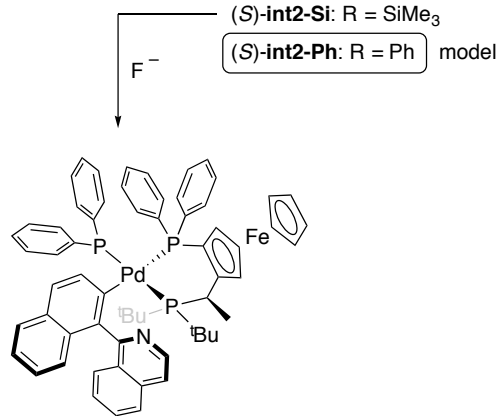

(S)-int3

Scheme 9. Two-step Transmetalation Process, and the Computed $\mathbf{P P h}_{3}$ Model

Thus, all possible transition structures for the approach of the nucleophilic phosphine were computed, maintaining in all cases similar distances for the coordination of the phosphine to palladium and decoordination of the isoquinoline-nitrogen from the metal (Figure 3). As mentioned before, there are eight main isomers for the int-1 type complexes, and for each of them we found at least two different transition structures, depending on the departing trajectory followed by the isoquinoline. Compare for example the two lowest in energy structures for the $\boldsymbol{S}$ enantiomer ( $\boldsymbol{S}$-TS2-a, $\boldsymbol{S}$ TS2-b), in which the isoquinoline ligand leaves the palladium sphere towards the lower or upper face, respectively. All of the possible alternatives were computed, resulting in a large range of activation energies (ca. $10 \mathrm{kcal} / \mathrm{mol}$ ), but only the most stable ones 


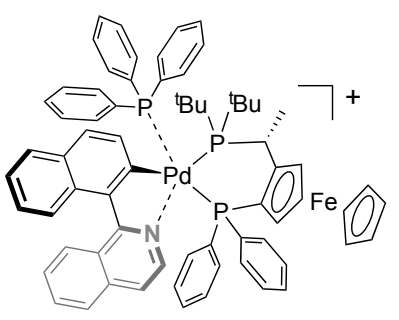

(S)-TS2-a

$\Delta \Delta \mathbf{G}^{\ddagger}=0$

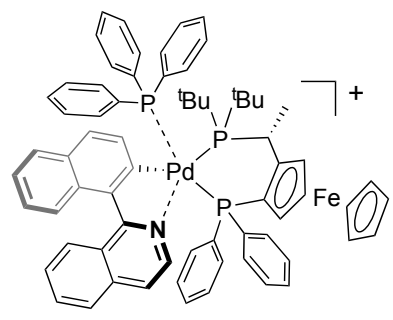

(S)-TS2-b

$\Delta \Delta \mathrm{G}^{\ddagger}=+0.9$

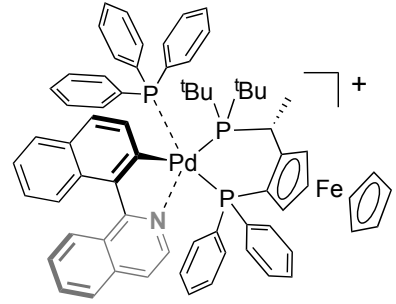

(R)-TS2-a

$\Delta \Delta \mathrm{G}^{\ddagger}=+4.2$

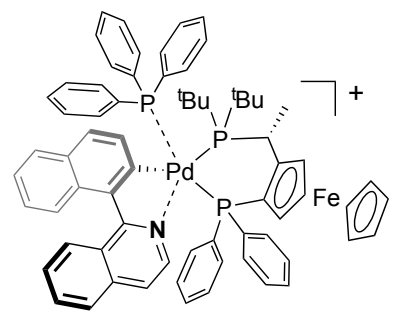

(R)-TS2-b

$\Delta \Delta \mathrm{G}^{\ddagger}=+4.3$
Figure 3. Most Stable Transition States for the Approach of $\mathbf{P P h}_{3}$ to the Pd center, computed at M06/6$31+G(d, p)($ iefpcm, THF $) / /$ B3LYP/6-31G $(d, p)$

are shown in Figure 3. To our delight, the most favored approach (S-TS2-a) is in agreement with the formation of the experimental major $\boldsymbol{S}$ enantiomer, and the difference with the lowest pro- $\boldsymbol{R}$ structure $(\boldsymbol{R}$-TS2-a) is $4.2 \mathrm{kcal} / \mathrm{mol}$, large enough to explain a high selectivity in the process. Even more, the second favored structure also corresponds to the $S$-enantiomer $(\boldsymbol{S}$-TS2-b, $+0.9 \mathrm{kcal} / \mathrm{mol})$. Taking the results of Schemes 8 and Figure 3 together, we are facing the typical situation where the minor, less stable isomer $(\boldsymbol{S}$ int1-L12) reacts faster than the major unreactive one (R-int1L12), nicely explaining the experimental stereoselectivity results (Figure 4). It is also important to note that the computed activation energy of the $(S)$-TS2-a is $\Delta G^{\ddagger}=25.2 \mathrm{kcal} / \mathrm{mol}$ from the separate

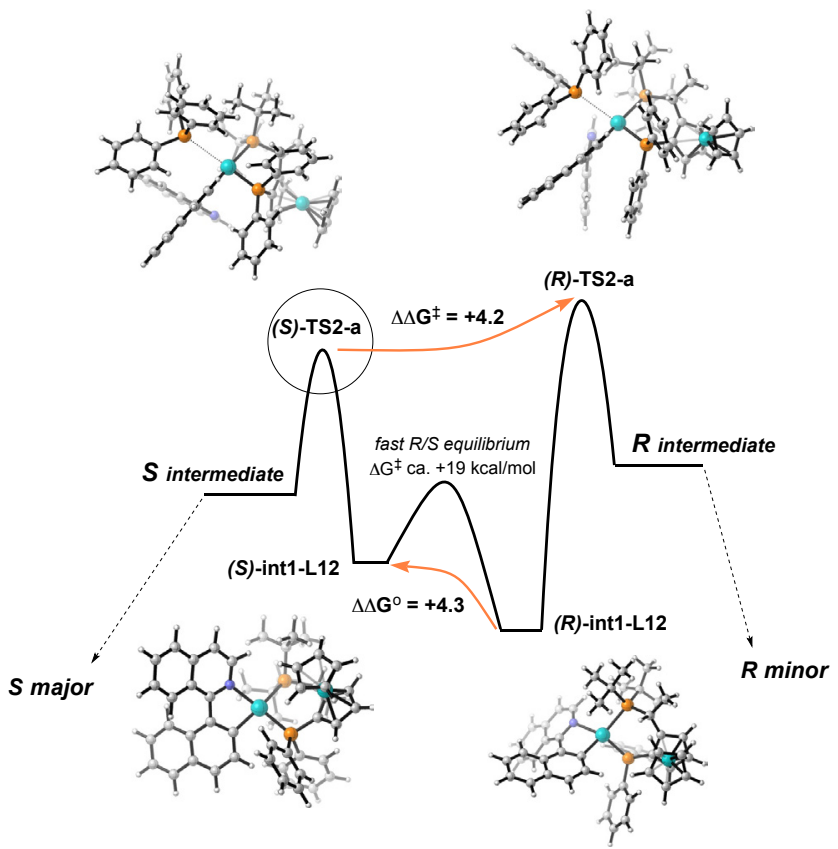

Figure 4. Energy diagram for the transmetallation step.
$\mathrm{PPh}_{3}$ and $(R)$-int1-L12, and can be safely considered the rate limiting step, as it is much larger than either isomerization, or reductive elimination. ${ }^{34}$

The final C-P reductive elimination step was also computed (Scheme 10), affording interesting data. First, the activation barrier for TS3 is very low comparing to the rest of energies found in this study $\left(\Delta \mathrm{G}^{\ddagger}=12.5 \mathrm{kcal} / \mathrm{mol}\right)$, making the whole process after transmetalation irreversible. Secondly, the rotation barrier for the int3-type intermediates and for the final QUINAP-type products raise to 34.7 and $32.5 \mathrm{kcal} / \mathrm{mol}$, respectively. Racemization processes at the final stages of the reaction are, thus, unfeasible, confirming that the formation of palladacycles by chelation with the nitrogen of the isoquinoline (like in int1) is a mandatory condition to allow the epimerization of the substrates.

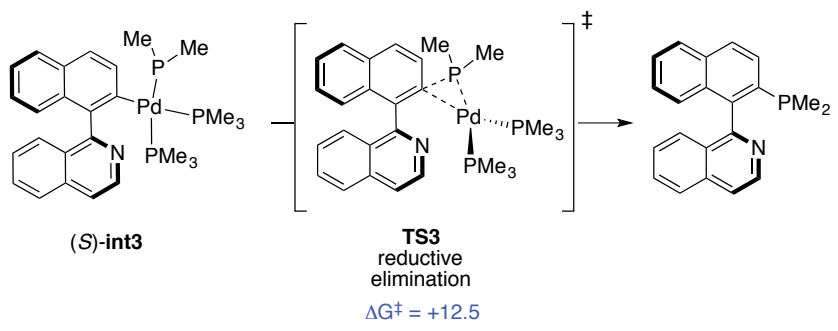

Scheme 10. Structure and Activation Energy of the C-P Reductive Elimination Step

Finally, we also checked the possible involvement of the palladium center in a Pd-H agostic bond (int4, Figure 5), which has been proposed by Virgil and Stolz ${ }^{21}$ to explain the epimerization of the oxidative addition intermediates without the intervention of the nitrogen atom. Our calculations show that the model complex int4 is remarkably more unstable $(\Delta \mathrm{G}=+9.3 \mathrm{kcal} / \mathrm{mol})$ than the simple int1-type palladacycle. This large energy difference is enough to completely discard the participation of int 4 in the mechanism.
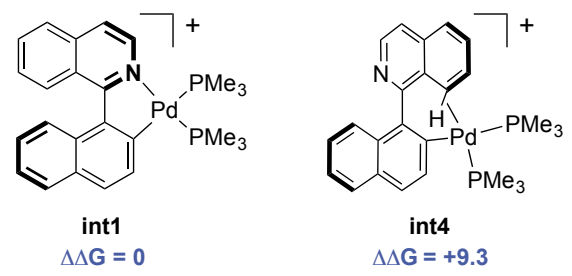

Figure 5. Comparison of Virgil-Stolz Proposal (int4) and Palladacycle int 1

\section{CONCLUSION}

In summary, the dynamic kinetic asymmetric $\mathrm{C}-\mathrm{P}$ coupling between heterobiaryl triflates or nonaflates and trimethylsilylphosphines appears as an efficient, general methodology for the asymmetric synthesis of QUINAP, PyPHOS, QUINAZOLINAP, and PINAP analogues. The collected experimental evidences and the results of the performed computational study allow to propose a mechanism based on the formation of cationic oxidative addition intermediates that, under the reaction conditions, undergo a fast interconversion. Coordination of the isoquinoline $\mathrm{N}$ atom to $\mathrm{Pd}$ is essential to facilitate this process. The calculations also show that the energy requirements for a dynamic kinetic process are met, since the fast equilibrating palladacyclic intermediates evolve through diastereomeric transmetalation steps of very large energy 
difference. The easiness of the final reductive elimination ensures the irreversibility of the process.

\section{ASSOCIATED CONTENT}

\section{Supporting Information}

The Supporting Information is available free of charge on the ACS Publications website at DOI: 10.1021/acscat.xxxxxx Experimental procedures, optimization studies, characterization data, NMR spectra for new compounds, and HPLC traces (PDF). Complete description of the computed structures and energies (PDF). Three-dimensional structural data of selected intermediates and transition states (pdb).

\section{AUTHOR INFORMATION}

\section{Corresponding Authors}

*abel.ros@iiq.csic.es

*ffernan@us.es

*enrique.gomez@ehu.es,

*jmlassa@iiq.csic.es.

\section{Notes}

The authors declare no competing financial interest.

\section{ACKNOWLEDGMENT}

The authors thank for technical and human support provided by IZOSGI SGIker of UPV/EHU, European funding [ERDF, ESF and FP7 (ITN ECHONET network MCITN-2012-316379)], Ministerio de Economía y Competitividad (grants CTQ2013-48164-C2-1-P and CTQ2013-48164-C2-2-P, contract RYC-2013-12585 for A.R), and the Junta de Andalucía (Grant 2012/FQM 1078).

\section{REFERENCES}

1. a) Doucet, H.; Fernández, E.; Layzell, T. P.; Brown, J. M. Chem. Eur. J. 1999, 5, 1320-1330. b) Maeda, K.; Brown, J. M. Chem. Commun. 2002, 310-311. c) Black, A.; Brown, J. M.; Pichon, C. Chem. Commun. 2005, 5284-5286.

2. Fernández, E.; Maeda, K.; Hooper, M. W.; Brown, J. M. Chem. Eur. J. 2000, 6, 1840-1846.

3. a) Morgan, J. B.; Miller, S. P.; Morken, J. P. J. Am. Chem. Soc. 2003, 125, 8702-8703. b) Trudeau, S.; Morgan, J. B.; Shrestha, M.; Morken, J. P. J. Org. Chem. 2005, 70, 9538-9544. c) Miller, S. P.; Morgan, J. B.; Nepveux, F. J. V.; Morken, J. P. Org. Lett. 2004, 6, 131-133. d) Kalendra, D. M.; Duenes, R. A.; Morken, J. P. Synlett 2005, 1749-1751. e) Ramírez, J.; Segarra, A. M.; Fernández, E. Tetrahedron: Asymmetry 2005, 16, 12891295.

4. a) Fleming, W. J.; Mueller-Bunz, H.; Lillo, V.; Fernandez, E.; Guiry, P. J. Org. Biomol. Chem. 2009, 7, 2520-2524.

5. a) Chen, C.; Li, X.; Schreiber, S. L. J. Am. Chem. Soc. 2003, 125, 10174-10175. b) Lim, A. D.; Codelli, J. A.; Reisman, S. E. Chem. Sci. 2013, 4, 650-654.

6. Miura, T.; Yamauchi, M.; Kosaka, A.; Murakami, M. Angew. Chem., Int. Ed. 2010, 49, 4955-4957.

7. a) Koradin, C.; Polborn, K.; Knochel, P. Angew. Chem., Int. Ed. 2002, 41, 2535-2538. b) Koradin, C.; Gommermann, N.; Polborn, K.; Knochel, P. Chem. Eur. J. 2003, 9, 2797-2811.

8. a) Taylor, A. M.; Schreiber, S. L. Org. Lett. 2006, 8, 143-146. For A ${ }^{3}-$ type reactions, see: b) Gommermann, N.; Koradin, C.; Polborn, K.; Knochel, P. Angew. Chem., Int. Ed. 2003, 42, 5763-5766. c) Gommermann, N.; Knochel, P. Chem. Eur. J. 2006, 12, 4380-4392. d) Dube, H.; Gommermann, N.; Knochel, P. Synthesis 2004, 2015-2025. e) Gommermann, N.; Gehrig, A.; Knochel, P. Synlett 2005, 2796-2798. f) Gommermann, N.; Knochel, P. Synlett 2005, 2799-2801. g) Aschwanden, P.; Stephenson, C.
R. J.; Carreira, E. M. Org. Lett. 2006, 8, 2437-2440. h) Ye, J.; Li, S.; Chen, B.; Fan, W.; Kuang, J.; Liu, J.; Liu, Y.; Miao, B.; Wan, B.; Wang, Y.; Xie, X.; Yu, Q.; Yuan, W.; Ma, S. Org. Lett. 2012, 14, 1346-1349. i) Lin, W.; Cao, T.; Fan, W.; Han, Y.; Kuang, J.; Luo, H.; Miao, B.; Tang, X.; Yu, Q.; Yuan, W.; Zhang, J.; Zhu, C.; Ma, S. Angew. Chem., Int. Ed. 2014, 53, 277-281.

9. a) Knopfel, T. F.; Zarotti, P.; Ichikawa, T.; Carreira, E. M. J. Am. Chem. Soc. 2005, 127, 9682-9683. b) Zarotti, P.; Knoepfel, T. F.; Aschwanden, P.; Carreira, E. M. ACS Catal. 2012, 2, 1232-1234.

10. a) Alcock, N. W.; Brown, J. M.; Hulmes, D. I. Tetrahedron: Asymmetry 1993, 4, 743-756. b) Doucet, H.; Brown, J. M. Tetrahedron: Asymmetry 1997, 8, 3775-3784. c) Lim, C. W.; Tissot, O.; Mattison, A.; Hooper, M. W.; Brown, J. M.; Cowley, A. R.; Hulmes, D. I.; Blacker, A. J. Org. Process Res. Dev. 2003, 7, 379-384. d) Fernández, E.; Guiry, P. J.; Connole, K. P. T.; Brown, J. M. J. Org. Chem. 2014, 79, 5391-5400 and references cited therein.

11. Milhau, L.; Guiry, P. J. Synlett 2011, 383-385.

12. Knoepfel, T. F.; Aschwanden, P.; Ichikawa, T.; Watanabe, T.; Carreira, E. M. Angew. Chem., Int. Ed. 2004, 43, 5971-5973.

13. Kwong, F. Y.; Yang, Q.; Mak, T. C. W.; Chan, A. S. C.; Chan, K. S. J. Org. Chem. 2002, 67, 2769-2777.

14. Cardoso, F. S. P.; Abboud, K. A.; Aponick, A. J. Am. Chem. Soc. 2013, 135, 14548-14551.

15. Thaler, T.; Geittner, F.; Knochel, P. Synlett 2007, 2655-2658.

16. Clayden, J.; Fletcher, S. P.; McDouall, J. J. W.; Rowbottom, S. J. M. J. Am. Chem. Soc. 2009, 131, 5331-5343.

17. Recent reviews: a) Zhang, D.; Wang, Q. Coord. Chem. Rev. 2015, 286, 1-16. b) Wencel-Delord, J.; Panossian, A.; Leroux, F. R.; Colobert, F. Chem. Soc. Rev. 2015, 44, 3418-3430. c) Cherney, A. H.; Kadunce, N. T.; Reisman, S. E. Chem. Rev. 2015, 115, 9587-9652. d) Pauline, L.; Manoury, E.; Poli, R.; Deydier, E.; Labande, A. Coord. Chem. Rev. 2016, 308, 131190. Selected references: e) Yin, J. J.; Buchwald, S. L. J. Am. Chem. Soc. 2000, 122, 12051-12052. f) Cammidge, A. N.; Crepy, K. V. L. Chem. Commun. 2000, 1723-1724. g) Sawai, K.; Tatumi, R.; Nakahodo, T.; Fujihara, H. Angew. Chem., Int. Ed. 2008, 47, 6917-6919. h) Uozumi, Y.; Matsuura, Y.; Arakawa, T.; Yamada, Y. M. A. Angew. Chem. Int. Ed. 2009, 48, 2708-2710. i) Shen, X.; Jones, G. O.; Watson, D. A.; Bhayana, B.; Buchwald, S. L. J. Am. Chem. Soc. 2010, 132, 11278-11287. j) Yamamoto, T.; Akai, Y.; Nagata, Y.; Suginome, M. Angew. Chem. Int. Ed. 2011, 50, 8844-8847. k) Wang, S.; Li, J.; Miao, T.; Wu, W.; Li, Q.; Zhuang, Y.; Zhou, Z.; Qiu, L. Org. Lett. 2012, 14, 1966-1969. 1) Tang, W.; Patel, N. D.; Xu, G.; Xu, X.; Savoie, J.; Ma, S.; Hao, M.; Keshipeddy, S.; Capacci, A. G.; Wei, X.; Zhang, Y.; Gao, J. J.; Li, W.; Rodriguez, S.; Lu, B. Z.; Yee, N. K.; Senanayake, C. H. Org. Lett. 2012, 14, 2258-2261. m) Zhou, Y.; Wang, S.; Wu, W.; Li, Q.; He, Y.; Zhuang, Y.; Li, L.; Pang, J.; Zhou, Z.; Qiu, L. Org. Lett. 2013, 15, 5508-5511.

18. a) Pedersen, J. R. Acta Chem. Scand. 1972, 26, 929-936. b) Brunner, H.; Olschewski, G.; Nuber, B. Synthesis 1999, 429-434. c) Tucker, S. C.; Brown, J. M.; Oakes, J.; Thornthwaite, D. Tetrahedron 2001, 57, 25452554. d) Baker, R. W.; Rea, S. O.; Sargent, M. V.; Schenkelaars, E. M. C.; Tjahjandarie, T. S.; Totaro, A. Tetrahedron 2005, 61, 3733-3743. e) Tanaka, S.; Suzuki, Y.; Matsushita, M.; Kitamura, M. Bull. Chem. Soc. Jpn. 2015, 88, 1726-1734.

19. Ros, A.; Estepa, B.; Ramírez-López, P.; Álvarez, E.; Fernández, R.; Lassaletta, J. M. J. Am. Chem. Soc., 2013, 135, 15730-15733.

20. Lassaletta, J. M.; Ros, A.; Fernández, R.; Estepa, B.; Ramírez-López, P. (CSIC, Universidad de Sevilla). Procedimiento de Síntesis de Compuestos Heterobiarílicos con Quiralidad Axial, Compuestos Obtenidos y Uso. ES Patent P201331068, July 12, 2013.

21. Bhat, V.; Wang, S.; Stoltz, B. M.; Virgil, S. C. J. Am. Chem. Soc., 2013, 135, 16829-16832.

22. $t \mathrm{BuMe}_{2} \mathrm{SiPPh}_{2} 2$ and $i \mathrm{Pr}_{3} \mathrm{SiPPh}_{2} 4$ were synthesized following previously described procedures, see: a) Hayashi, M.; Matsuura, Y.; Watanabe, Y. Tetrahedron Lett. 2004, 45, 1409-1411. b) Trepohl, V. T.; Oestreich, M. Chem. Commun. 2007, 3300-3302.

23. Other bases such as $\mathrm{Ba}(\mathrm{OH})_{2}, \mathrm{~K}_{3} \mathrm{PO}_{4}, \mathrm{KF}, \mathrm{Cs}_{2} \mathrm{CO}_{3}$ and $\mathrm{K}_{2} \mathrm{CO}_{3}$ were tested using $\mathbf{L} \mathbf{1}$ as the ligand, but lower conversions were observed.

24. For a review on the synthesic utility of silylphosphines see: a) Hayashi, M. Chem. Rec. 2009, 9, 236-245. Pd-catalyzed synthesis of tri- 
arylphosphines from aryliodides and silylphosphines: b) Tunney, S. E.; Stille, J. K. J. Org. Chem. 1987, 52, 748-753. c) Enantioselective arylation of silylphosphines: Chan, V. S.; Bergman, R. G.; Toste, F. D. J. Am. Chem. Soc. 2007, 129, 15122-15123. Nickel-catalyzed synthesis of triarylphosphines from aryl nitriles or aryl chlorides: c) Sun, M.; Zhang, H.-Y.; Han, Q.; Yang, K.; Yang, S.-D. Chem. Eur. J. 2011, 17, 9566-9570. d) Sun, M.; Zang, Y.-S.; Hou, L.-K.; Chen, X.-X.; Wei Sun, W.; Yang, S.-D. E. Eur. J. Org. Chem., 2014, 6796-6801.

25. a) Bermejo, A.; Ros, A.; Fernández, R.; Lassaletta, J. M. J. Am. Chem. Soc. 2008, 130, 15798-15799. b) Ros, A.; Estepa, B.; Bermejo, A.; Álvarez, E.; Fernández, R.; Lassaletta, J. M. J. Org. Chem. 2012, 77, 4740-4750.

26. a) Tappe, M. J. F.; Trepohl, V. T.; Oestreich, M. Synthesis, 2010, 3037-3062. b) Li, Y.-M.; Tang, S.-D. Synlett, 2013, 1739-1744. c) Wauters, I.; Debrouwer, W.; Stevens, C. V. Beilstein J. Org. Chem. 2014, 10, 1064-1096. d) Glueck, D. S. Top. Organomet. Chem. 2010, 31, 65-100.

27 . The $S$ configuration was assigned by chemical correlation. See supporting information for details.

28. Triflates were stored in the fridge for months to prevent the formation of triflic acid traces, affording reproducible enantiomeric excesses throughout this study without the need of further purifications.

29. Trepohl, V. T.; Fröhlich, R.; Oestreich, M. Tetrahedron 2009, 65, 6510-6518. The deprotonation at $-78{ }^{\circ} \mathrm{C}$ of commercially available phosphines, followed by trapping of the corresponding phosphide with $\mathrm{ClSiMe}_{3}$, gave the silylphosphine crudes with purity higher than $90 \%$. Further purification by distillation in vacuo (see SI) afforded the pure silylphosphines 5ae in $71-92 \%$ isolated yields.
30. Nonaflates (nonafluorobutanesulfonates) have been broadly used in synthesis as an alternative to triflates due to their higher stability and similar reactivity: Högermeier, J.; Reissig H.-U. Adv. Synth. Catal. 2009, 351, 2747-2763.

31. Gaussian 09, Revision D.01; M. J. Frisch, G. W. Trucks, H. B. Schlegel, G. E. Scuseria, M. A. Robb, J. R. Cheeseman, G. Scalmani, V. Barone, B. Mennucci, G. A. Petersson, H. Nakatsuji, M. Caricato, X. Li, H. P. Hratchian, A. F. Izmaylov, J. Bloino, G. Zheng, J. L. Sonnenberg, M. Hada, M. Ehara, K. Toyota, R. Fukuda, J. Hasegawa, M. Ishida, T. Nakajima, Y. Honda, O. Kitao, H. Nakai, T. Vreven, J. A. Montgomery, Jr., J. E. Peralta, F. Ogliaro, M. Bearpark, J. J. Heyd, E. Brothers, K. N. Kudin, V. N. Staroverov, T. Keith, R. Kobayashi, J. Normand, K. Raghavachari, A. Rendell, J. C. Burant, S. S. Iyengar, J. Tomasi, M. Cossi, N. Rega, J. M. Millam, M. Klene, J. E. Knox, J. B. Cross, V. Bakken, C. Adamo, J. Jaramillo, R. Gomperts, R. E. Stratmann, O. Yazyev, A. J. Austin, R. Cammi, C. Pomelli, J. W. Ochterski, R. L. Martin, K. Morokuma, V. G. Zakrzewski, G. A. Voth, P. Salvador, J. J. Dannenberg, S. Dapprich, A. D. Daniels, O. Farkas, J. B. Foresman, J. V. Ortiz, J. Cioslowski, and D. J. Fox, Gaussian, Inc., Wallingford CT, 2013

32. See Supporting Information for Computational Details.

33. Cortright, S. B.; Yoder, R. A.; Jeffrey N. Johnston J. N. Heterocycles, 2004, 62, 223-227.

34. We assume that the barriers of isomerization or reductive elimination will not be strongly affected if the real ligand $\mathbf{L 1 2}$ is used instead of the model bis- $\mathrm{PMe}_{3}$ surrogate. 


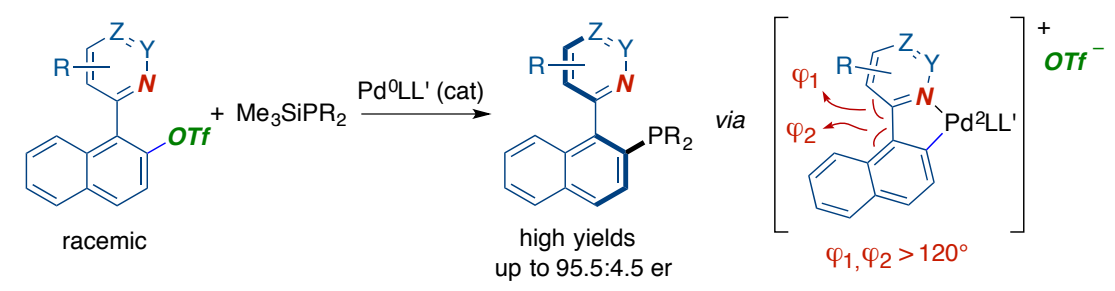

